\title{
Risk-Return in the Stock Market: A Wavelet Approach
}

\author{
Rasheed Adegbola Bello* \\ Global Business School, Business Management Manchester Campus, Manchester, UK \\ Email: belmath4@yahoo.com
}

How to cite this paper: Bello, R.A. (2021) Risk-Return in the Stock Market: A Wavelet Approach. Journal of Mathematical Finance, 11, 651-669.

https://doi.org/10.4236/jmf.2021.114035

Received: September 10, 2021

Accepted: November 21, 2021

Published: November 24, 2021

Copyright (c) 2021 by author(s) and Scientific Research Publishing Inc. This work is licensed under the Creative Commons Attribution International License (CC BY 4.0).

http://creativecommons.org/licenses/by/4.0/

\begin{abstract}
The study utilized continuous wavelet to explore the co-movement of equities of four countries: France, Germany, the UK and the US. The daily data were extracted from January 2000 to May 2020 but converted to weekly data to limit the computational burden. The paper established co-movement among the four equity markets. However, the strength of the co-movement varies across time horizons. Similarly, higher co-movement was found in the long run than in the short run. Regional differences were also established, with the European equity markets exhibiting similar dynamics with their US counterpart.
\end{abstract}

\section{Keywords}

Stock Prices, Equity Market, Risk, Return, Wavelet Analysis

\section{Introduction}

The equity market is viewed as an important economic indicator. A considerable decline in equity prices is indicative of a future recession, while a massive rise in equity prices is suggestive of future economic growth. Despite its predictive power, equity prices exhibit volatility and often difficult to predict. However, limiting the volatility effect requires understanding the dynamic of risk relative to the expected returns of stock market investment [1]. This has spurred interest in the risk-return trade-off. However, financial theories emphasise a need to compensate risk-averse investors for additional risk-bearing in the market. Similarly, [2] posited that the risk-return relation motivates theoretical models which explain observed volatility patterns of the equity market.

${ }^{*}$ I am very grateful to Luís Aguiar-Conraria and Maria Joana Soares, both of University of Minho, Portugal for providing their toolboxes on this website,

https://sites.google.com/site/aguiarconraria/joanasoares-wavelets/the-astoolbox. 
While this underpins the rational asset pricing models, the Capital Asset Pricing Model (CAPM) emphasises a positive link between returns and risk in the equity market. More so, the Intertemporal Capital Asset Pricing Model (ICAPM) emphasises that the conditional expected excess returns on the equity market have a positive link with the conditional market volatility [3] [4]. However, empirical studies on the risk-return trade-off have been mixed. [5] established a negative link between risk and returns. In contrast, [6] established a positive link between risk and return. Additionally, a group of studies contended that the increasing globalisation of financial architecture has a substantial impact on the risk-return trade-off.

This financial globalisation enables the ease of investment diversification from a risky environment to a lesser risky environment. This often leads to co-movement in the equity market based on the risk and returns in different markets. This comovement assists in the international diversification of investments and the flightto-quality for investors during financial crises. Despite its significance, empirical studies on the co-movement of equity markets largely utilised time series analysis. However, time series analysis has some drawbacks. [7] argued that the equity market comprises heterogeneous trading agents with divergent investment horizons. While this might trigger a complex dynamic of equity prices at different periods, [8] claimed that this might propagate a long memory in stock return volatility.

Similarly, financial markets involve heterogeneous investors with different investment horizons. [9] contended that risk-return trade-off is likely to be dependent on the investment horizons of investors. With the inability of timedomain analysis to address these issues, some studies adopted Fourier analysis to mitigate these problems. However, Fourier analysis requires stable statistical properties to be appropriate for time series analysis, suggesting that it is suitable for the stationary time series. [10] posited that financial time series are typically non-stationary and exhibit complicated patterns, such as structural changes and volatility clustering. Similarly, time information is lost with Fourier analysis and would be difficult to distinguish transient relationship from a permanent one. Additionally, the loss of time information could hinder the opportunity to identify structural changes.

Wavelet analysis refines Fourier analysis and offers a window of opportunity to see both the forest and the trees [11]. In wavelet analysis, the level of localisation is automatically adapted in time and frequency with only a narrow timewindow required to examine high-frequency but allowing a wide time-window during the investigation of low-frequency components [12]. With the co-movement analysis accounting for the distinction between short- and long-term investors [13], this study used wavelet analysis to evaluate the co-movement of stock market returns in different countries. This offers opportunities to evaluate co-movement across timescale and explores the dynamics of different markets that are hidden in time series analysis. 


\section{Literature Review}

There is a huge body of literature exploring the risk-return relationship. While the studies used various models, they explored this link from multiple perspectives. For instance, [14] used the risk and stock returns to evaluate the spillover effects between the stock market and global oil prices. The study found that the spillover is linked to shocks rather than volatility. [15] adopted the binormal GARCH model to risk-return tradeoff and established a positive risk-return link in eleven of the fourteen markets evaluated. [16] also explored the risk-return tradeoff and found a positive risk-return tradeoff for low volatility states. However, it established reduced or non-significant findings for high volatility states. [6] also utilised a model that allows the evolution of the relevance of the riskreturn tradeoff and autocorrelation to explore the link between the aggregate stock return's conditional mean and variance. Although the study reported a positive link between risk and return, the significance of the risk-return link fluctuates with the information-flow level. Specifically, the study established increases in market-wide persistence returns during the low-volatility period.

Similarly, [17] applied the fractionally integrated exponential GARCH-in-mean (FIEGARCH-M) model to investigate the effect of financial crises on the leverage effect and risk-return tradeoff. While the study established a significant positive risk-return tradeoff during financial crises, this was insignificant during noncrisis periods. However, the leverage effect was negative during crisis and noncrisis periods but increased by approximately $50 \%$ in magnitude during crisis periods. [18] investigated the intertemporal risk-return link using the non-parametric Bry-Boschan approach. The study revealed a significantly positive riskreturn link in bull markets but a negative link in bear markets. While [19] utilised a TSV-GARCH (p,q)-Risk-Mean model to evaluate the link between stock market risk and return premium, the study established four stock market displays of dynamic processes. Furthermore, [20] examined the risk-return tradeoff and found a strong time-varying risk-return tradeoff.

While studies exploring the risk-return relationship typically utilised the timedomain analysis, they require stationary time series. However, economic and financial time series are typically non-stationary. The time-domain analysis focuses on the time dimension of a series and limits the exploration of the frequency dynamics. Wavelet provides the opportunity to see the hidden dynamics in such a series.

\section{Methodology}

Although this paper utilised wavelet analysis, Fourier analysis serves as a foundation for wavelet analysis. The Fourier series is a vital component of the Fourier analysis and emphasises that any periodic function can be written as an infinite sum of sine and cosine functions. The Fourier representation of a square-integrable function $g \in L^{2}[-\pi, \pi]^{1}$ is given by

${ }^{1} g$ belongs to the square-integrable function space $L^{2}[-\pi, \pi]$ if $\int_{-\pi}^{\pi} g^{2}(x) \mathrm{d} x<\infty$. 


$$
g(x)=\frac{1}{2} a_{0}+\sum_{n=1}^{\infty}\left(a_{n} \cos (n x)+b_{n} \sin (n x)\right)
$$

where $a_{n}$ and $b_{n}$ represent Fourier coefficients of $g(x)$. Based on the orthogonality of sine and cosine functions, $a_{n}$ and $b_{n}$ are expressed as

$$
\begin{aligned}
& a_{n}=\frac{1}{\pi} \int_{-\pi}^{\pi} g(x) \cos (n x) \mathrm{d} x \\
& b_{n}=\frac{1}{\pi} \int_{-\pi}^{\pi} g(x) \sin (n x) \mathrm{d} x
\end{aligned}
$$

The Fourier transform $X(\omega)$ of a complex-valued, continuous signal $x(t)$ is given by

$$
X(\omega)=\int_{-\infty}^{\infty} x(t) \mathrm{e}^{i \omega t} \mathrm{~d} t
$$

with the angular frequency $\omega=2 \pi f$ and $f$ is the frequency in Hertz. However, the Fourier transform lacks local information and only allows the evaluation of a signal in the frequency domain [21]. It is often important to investigate a signal in both frequency and time domains. A wavelet analysis augments the Fourier analysis by localising small-windowed basis functions in time and scale and enabling them to capture non-stationary and aperiodic signals. Wavelets functions are defined over a finite domain and offer a suitable way of representing a complex signal and decomposing data into various frequency components for individual analysis. A wavelet function $\psi_{\tau, s}$ is a function generated from dilations and translations of a basis function $\psi$ called mother wavelet:

$$
\psi_{\tau, s}=\frac{1}{\sqrt{|s|}} \psi\left(\frac{t-\tau}{s}\right), \tau, s \in \mathbb{R}, s \neq 0
$$

where $\tau$ is the scaling parameter measuring the extent of compression or scale $\mathrm{e}^{2}$, and $s$ is the translation parameter determining the time location of the wavelet. The function $\psi_{\tau, s}(t)$ must satisfy some conditions to be considered a wavelet $^{3}$. The continuous wavelet transforms of a time-series $x_{t} \in L^{2}(\mathbb{R})$ concerning the wavelet function is defined by

$$
W_{x, \psi}(\tau, s)=\left\langle x, \psi_{\tau, s}\right\rangle=\int_{-\infty}^{\infty} x_{t} \frac{1}{\sqrt{|s|}} \psi^{*}\left(\frac{t-\tau}{s}\right) \mathrm{d} t
$$

with the ${ }^{\star}$ representing the complex conjugate. Although there are various types of wavelet, the Morlet wavelet is commonly used due to its optimal joint timefrequency concentration [23]. The Morlet wavelet is a complex wavelet that yields complex transforms and it is defined by

$$
\psi_{\omega_{0}}=\pi^{\frac{-1}{4}} \mathrm{e}^{i \omega_{0} t} \mathrm{e}^{\frac{-t^{2}}{2}}
$$

with $\omega_{0}$ being the localisation parameter in the frequency domain. With the

${ }^{2}$ With $|s|<1$, the wavelet $\psi_{\tau, s}(t)$ becomes smaller and corresponds mainly to higher frequencies. But with $|s|>1$, the wavelet $\psi_{\tau, s}(t)$ becomes larger and corresponds mainly to lower frequencies. ${ }^{3}$ See [22] for details. 
Euler's relations, $\mathrm{e}^{i \omega_{0} t}=\cos \omega_{0} t+i \sin \omega_{0} t$, Equation (7) becomes:

$$
\psi_{\omega_{0}}=\pi^{\frac{-1}{4}}\left(\cos \omega_{0} t+i \sin \omega_{0} t\right) \mathrm{e}^{\frac{-t^{2}}{2}}
$$

The choice of $\omega_{0}=6$, resulting in $f=\frac{6}{2 \pi s} \approx \frac{1}{s}$, is the commonest choice, and this yields some appealing results ${ }^{4}$. While this paper utilised continuous wavelet to detect hidden information in the traditional time domain, it used four continuous wavelet tools. The first tool is the wavelet-power spectrum or scalogram $\operatorname{WPS}_{x}(\tau, s)$ which measures the local variance of the time-series, $x(t)$, in the time-frequency domain. It is defined by

$$
\operatorname{WPS}_{x}(\tau, s)=\left|W_{x, \phi}(\tau, s)\right|^{2}
$$

The wavelet-power spectrum is used to highlight the variability of equity returns in each of the countries in the sample. While wavelet coherency is the second tool used in the study, it is analogous to covariance. It is used to detect and measure the relationship between two variables. The wavelet coherency between two series, $x(t)$ and $y(t)$ is computed as

$$
R_{x y}=\frac{\left|S\left(W_{x y}\right)(\tau, s)\right|}{\sqrt{S\left(\left|W_{x x \tau, s}\right|\right)} S\left(\left|W_{y y}(\tau, s)\right|\right)}
$$

where $W_{x}$ and $W_{y}$ represent the wavelet transform of $x$ and $y$, respectively; $W_{x y}(\tau, s)$ represents the cross-wavelet power of $x(t)$ and $y(t) ; W_{x x}(\tau, s)$ and $W_{y y}(\tau, s)$ represent the wavelet power of $x(t)$ and $y(t)$, respectively; $S$ signifies a smoothing operator in time and scale. In the paper, the degree of coherency between stock returns of two countries is evaluated, with the coherency considered for the typical business cycle band: fluctuations lasting for more than two years but less than eight years. The wavelet phase-difference is the third tool used, and it identified the lead and the lag variables between two variables under considerations. The phase-difference $\phi_{x, y}(\tau, s)$ between two series $x$ and $y$ is calculated from both the imaginary $\mathfrak{I}($.$) and the real part \mathfrak{R}($.$) of the cross-$ wavelet transform. It is expressed in radians with possible values, $\phi_{x, y}(\tau, s) \in[-\pi, \pi]$, and calculated $a s^{5}$

$$
\phi_{x, y}(\tau, s)=\arctan \left(\frac{\mathfrak{I}\left(W_{x y}(\tau, s)\right)}{\mathfrak{R}\left(W_{x y}(\tau, s)\right)}\right)
$$

${ }^{4}$ See [24] for a detailed description.

${ }^{5}-\pi<\phi_{x, y}(\tau, s) \leq \frac{-\pi}{2}$ implies that $x$ and $y$ are anti-phase with $x$ leading. $\frac{-\pi}{2} \leq \phi_{x, y}(\tau, s)<0$ implies that $x$ and $y$ are in-phase with $y$ leading. $0<\phi_{x, y}(\tau, s) \leq \frac{\pi}{2}$ implies that $x$ and $y$ are in-phase with $x$ leading. $\frac{\pi}{2} \leq \phi_{x, y}(\tau, s)<\pi$ implies that $x$ and $y$ are anti-phase with $y$ leading. At the margin, $\phi_{x, y}(\tau, s)=0$ implies that the series are totally in-phase while $\phi_{x, y}(\tau, s)=\pi$ implies the series are totally anti-phase. 
The increasing integration of equity market [25] has seen the impact of one market on another. In evaluating the co-movement between two equity markets, this study used a fourth continuous wavelet tool-partial wavelet coherency-to evaluate the link between two markets after eliminating the effects of other markets. The complex partial wavelet coherency between $x$ and $y$ after eliminating the effect of $z$ is given by

$$
\rho_{x y . z}=\frac{\rho_{x y}-\rho_{x z} \overline{\rho_{y z}}}{\sqrt{\left(1-R_{x z}^{2}\right)\left(1-R_{y z}^{2}\right)}} .
$$

The partial wavelet coherency $R_{x y . z}$ of $x$ and $y$ after eliminating the effect of $z$ is the absolute value of the complex partial wavelet coherency. Similarly, the partial phase-difference $\phi_{x y . z}$ of $x$ over $y$ is the phase-angle of $\rho_{x y . z}{ }^{6}$.

\section{Data and Empirical Results}

The data consists of equity market indexes in four countries. These countries include three European countries-France, Germany and the UK and one in North America-the USA. These countries were chosen due to their financial market size and similar market architecture. The data was downloaded from Datastream website $^{7}$. Daily equity index data was used for each country and covered the period January 2000 to May 2020. However, the data was converted to weekly data to reduce the computational burden. Table 1 provides descriptive statistics for equity indexes for sampled countries.

Germany and the USA recorded the maximum $(13,699.48)$ and minimum (695.19) weekly stock returns, respectively. While the mean index hovers between 1603.09 and 7525.42, the USA registered the lowest mean index while Germany had the highest mean. The UK FTSE 100 exhibited the highest variability, as shown with a variance of $1,028,867.91$. However, USA S \& P 500 exhibited the lowest volatility. All indexes, except UK FTSE 100, are positively skewed based on their positive skewness values. This implies that they are associated with long-right tails and comprised higher values around their means. Similarly, all indexes are platykurtic, with Kurtosis lower than 3. This implies that they have fewer outliers and thinner tails than a normal distribution.

Figure 1 presents the wavelet power spectrum for equity indexes for four

Table 1. Descriptive statistics.

\begin{tabular}{cccccccc}
\hline Country & Observations & Minimum & Maximum & Mean & Variance & Skewness & Kurtosis \\
\hline France & 1065 & 2540.96 & 6822.74 & 4453.57 & $855,181.23$ & 0.20 & -0.80 \\
Germany & 1065 & 2318.96 & 13699.48 & 7525.42 & $8,524,529.93$ & 0.42 & -0.93 \\
UK & 1065 & 3452.91 & 7794.426 & 5894.22 & $1,028,867.91$ & -0.27 & -0.71 \\
USA & 1065 & 695.19 & 3368.68 & 1603.09 & $376,897.69$ & 0.98 & -0.12 \\
\hline
\end{tabular}

${ }^{6}$ See [24] for the general formula for $n$ variables.

${ }^{7}$ The following indexes are used to represent each country: France CAC 40, Germany DAX, UK FTSE 100 and US S \& P 500. 

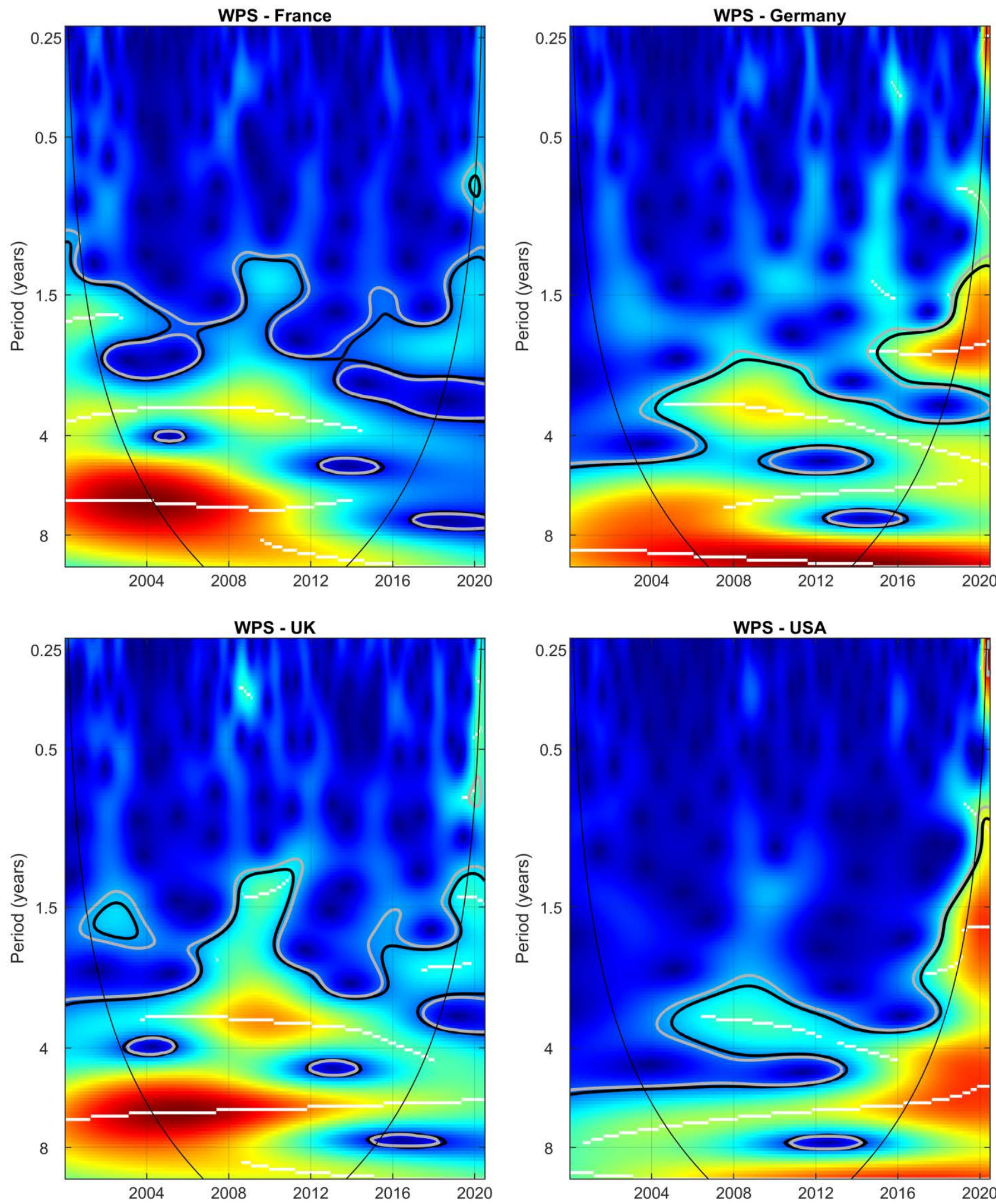

Figure 1. Equity indexes and their wavelet power spectra.

countries in our sample. The power spectrum is akin to present the descriptive statics in the time-frequency domain. The horizontal axis represents the time horizon for the series, while the vertical axis shows the period. With the inverse 
relationship between the period and frequency, a low period corresponds to high frequency while a high period reflects low frequency. Similarly, the black conical line is the cone of influence (COI) and represents the region where edge effects are essential. This is the region where unavoidable artefacts appear when executing the continuous wavelet transform. The results are very unreliable outside this line and must be interpreted with a caution (See [24] for more details.. With the wavelet-power spectrum measuring the local variance, the variability level is differentiated by a colour spectrum. The colour spectrum spans blue, which signifies low variability, while red indicates high variability. While the white lines in power spectra signify local maxima, the black and grey contours signify $5 \%$ and $10 \%$, respectively. The high variability is experienced as from 1.5 years for all the countries. The high variability is visible in the three European countries, implying that stock market indices experienced huge swings. While it is shown between 2004 and 2014 in France and the UK, it extended until 2016 in Germany.

The high synchronised variability in three European countries explains the steady increasing convergence in the European equity market. Similarly, high volatility explains the volatile nature of the European equity market. In particular, it reflected the various shocks within this period, culminating in the global financial crisis of 2007/2018 and the European financial crisis of 2010. Additionally, the Euro adoption in the Eurozone resulted in the convergence of the equity market in the zone and synchronisation with the non-Eurozone country, the UK. In contrast, the US equity market exhibited a different dynamic compared to the other three countries-France, Germany and the UK. Although the S \& P 500 index showed some level of variability, it is more stable than the other three indices, except around 2014.

Figure 2 shows the wavelet coherency and phase difference between France and the other three countries in the sample. While the interpretation of the wavelet coherency is similar to that of the wavelet power spectrum, the latter focused on the variance of a series while the former emphasised variance of the relationship between two series across timescale. Although the regions of high coherency vary across countries, there are many regions of high coherency between France and these countries. The coherency between France and Germany is statistically significant in almost all regions. While the same applies to the coherency between France and the UK, the level of coherency is relatively weak between 2013 and 2018 and within six months and a four-year period. In contrast, the high coherency between France and the USA covers limited regions, which essentially covers the period 2002 and 2014. Despite the varying coherency regions, Figure 2 shows that France mostly leads all three countries within the lower periods ( 2 - 4 years) between 2002 and 2014 in phase relation. The phase relationship implies that two stock market indices follow the same direction. With France being the leading market in this relation, it suggests that it facilitates the market dynamics. Precisely, an increase in CAC 40 index will propel an increase in other indices, while a decline in CAC 40 index will cause a decline 


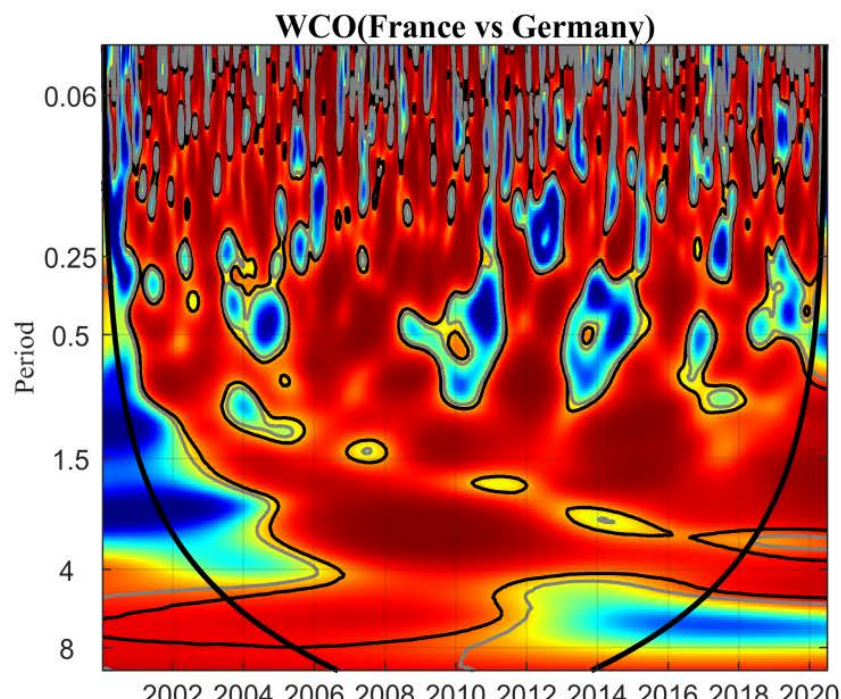

2002200420062008201020122014201620182020

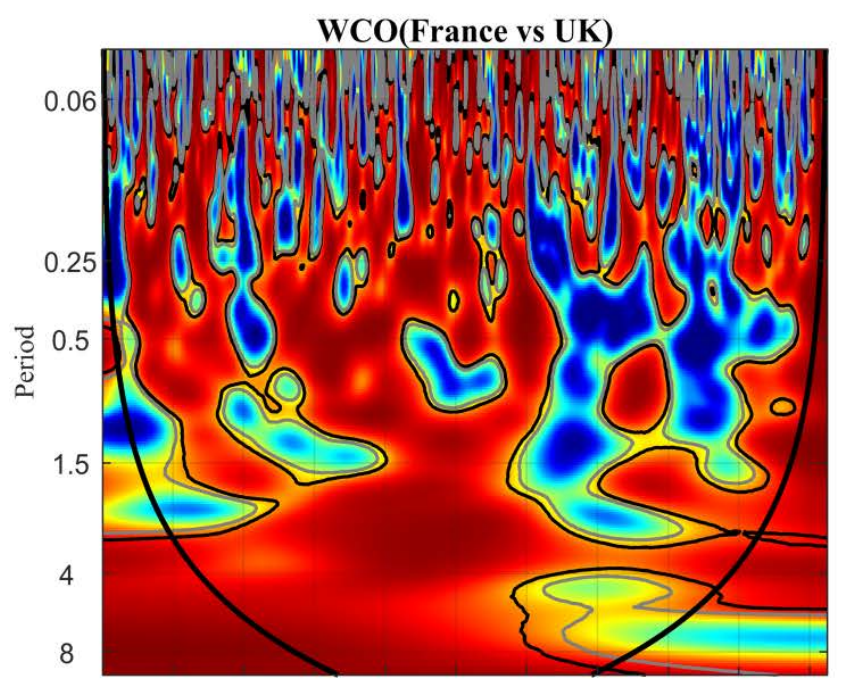

2002200420062008201020122014201620182020

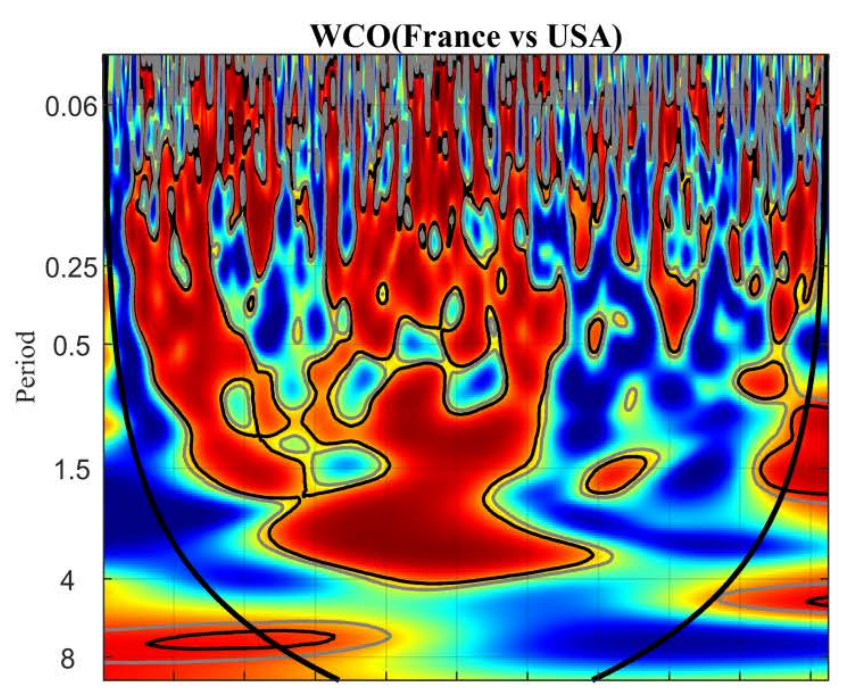

2002200420062008201020122014201620182020
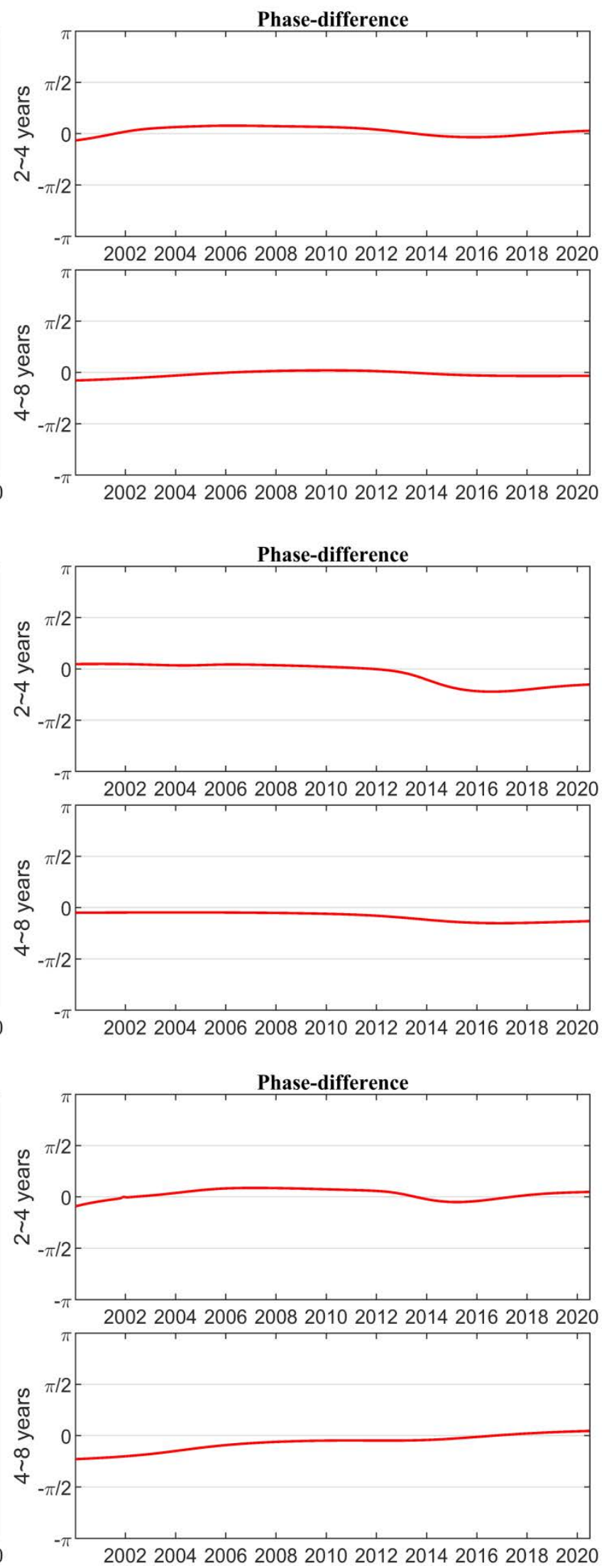

Figure 2. Wavelet coherency between France and other countries. 
in other indices. Within this period, the phase difference lies between 0 and $\frac{\pi}{2}$.

However, France lags other countries afterwards, implying that the other three indices drive the CAC 40 direction.

There is a contrasting scenario in the higher periods ( $4-8$ years) compared to the lower periods ( 2 - 4 years). While lower periods represent the short-run dynamics, higher periods signify the long-run dynamics. In higher periods, France lags other countries in phase relations, with the phase difference lying between 0 and $\frac{\pi}{2}$. Although France and Germany exhibited these relationships between 2002 and 2014, France and the UK exhibited anti-phase relations in the entire sample space. An anti-phase relation shows that the two indices move in different directions. Specifically, increases in France CAC 400 will lead to decreases in the UK FTSE 100 and vice versa. While the relationship between France and the USA reflected the same, it only lasted until 2014.

Figure 3 shows the wavelet coherency and phase difference between Germany and two other countries-the UK and the USA. The region of high coherency mimics that exhibited between France and other countries. Essentially, it covers various regions from three months. Prior to this period, there was a lot of noise in the coherency. However, the coherency between Germany and the UK covers a bigger region than the one between Germany and the USA. The relation in lower periods ( 2 - 4 years) is essentially an anti-phase relation, but they exhibited a mixed relationship in higher periods ( $4-8$ years). In lower periods, Germany lags the UK in an anti-phase relation between 2002 till the end of the sample period, with the phase difference lying between $-\frac{\pi}{2}$ and 0 . However, Germany and the USA have a mixed relationship in lower periods. The USA led Germany in an anti-phase relation between 2002 and 2005, but both countries' equity indexes synchronised between 2006 and 2012, with the phase difference of 0 . The relationship reverted to an anti-phase relation after 2012, with the USA leading. The dynamic in lower periods repeat itself in higher periods. Like lower periods, the UK leads Germany in an anti-phase relation. On the other hand, the USA leads Germany in an anti-phase relation between 2002 and 2012, while Germany leads in a phase relation afterwards.

Figure 4 shows the wavelet coherency and the phase difference between the UK and the USA. The UK leads the USA in a phase relation after 2004 in the lower periodic band (2 - 4). However, the USA leads the UK in a phase relation in the higher periodic band $(4-8)$ before the financial crisis of $2007 / 2008$, with the phase difference lying between $-\frac{\pi}{2}$ and 0 . However, the UK leads the US after the financial crisis in a phase relation, with the phase difference lying between 0 and $\frac{\pi}{2}$.

Although the wavelet coherency is between a pair of countries, the increasing integration of global financial architecture requires eliminating the effect of other 

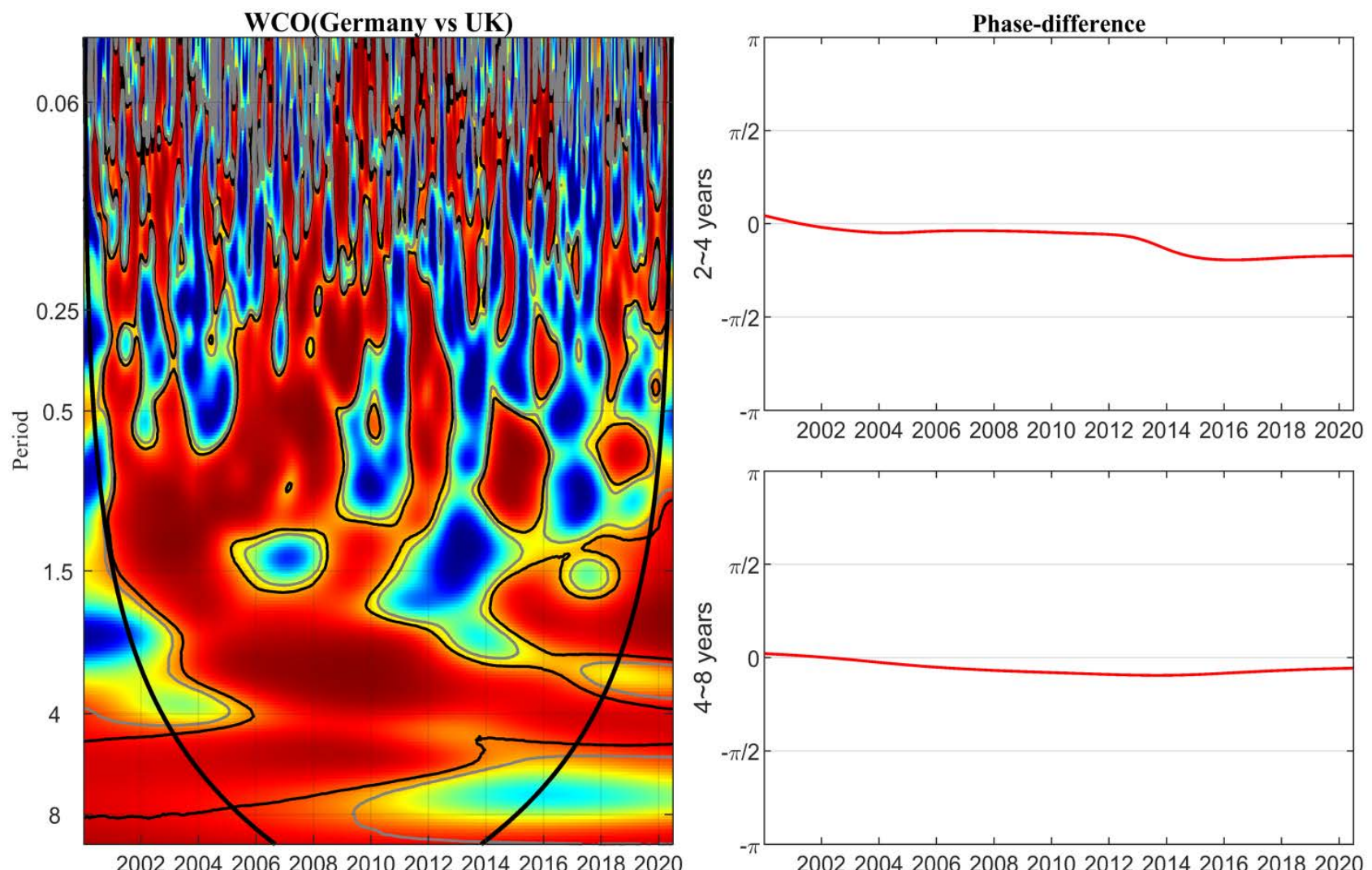

2002200420062008201020122014201620182020
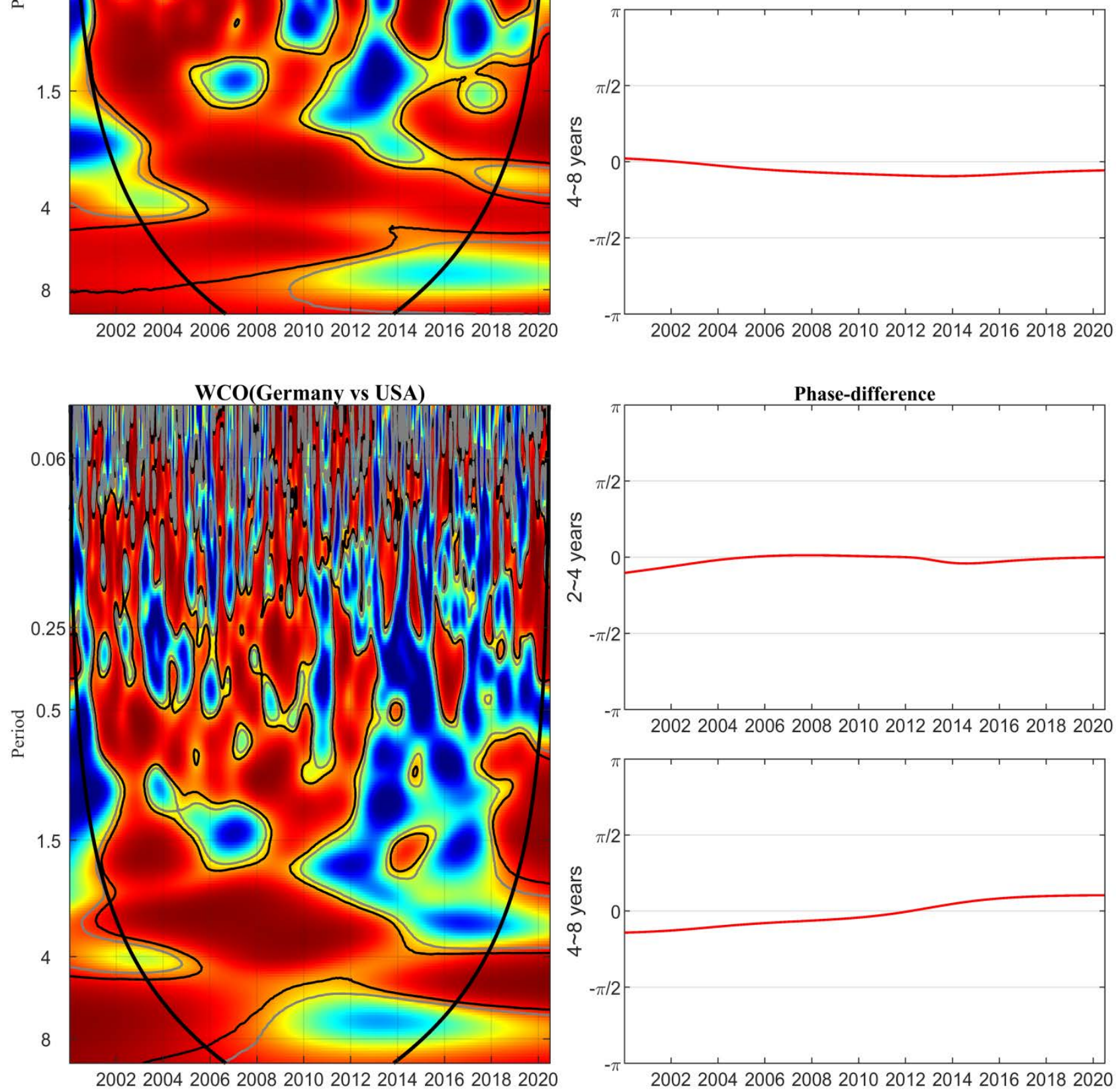

Figure 3. Wavelet coherency between Germany and other countries.

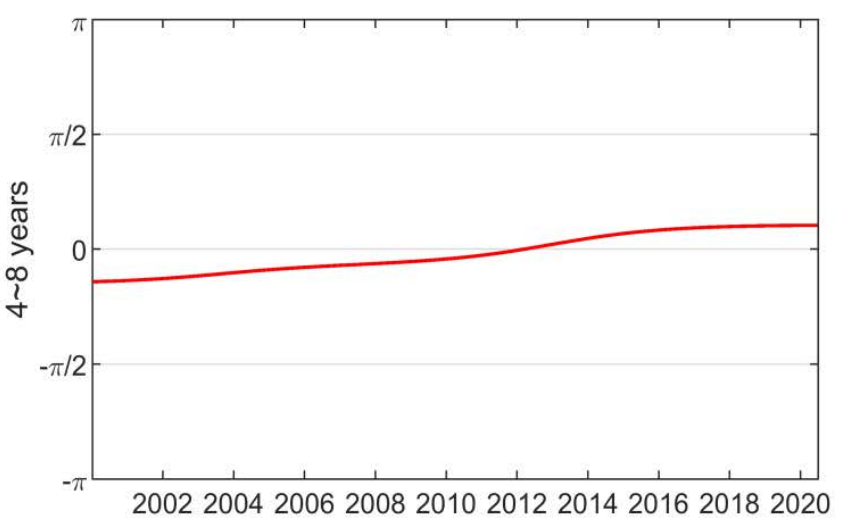



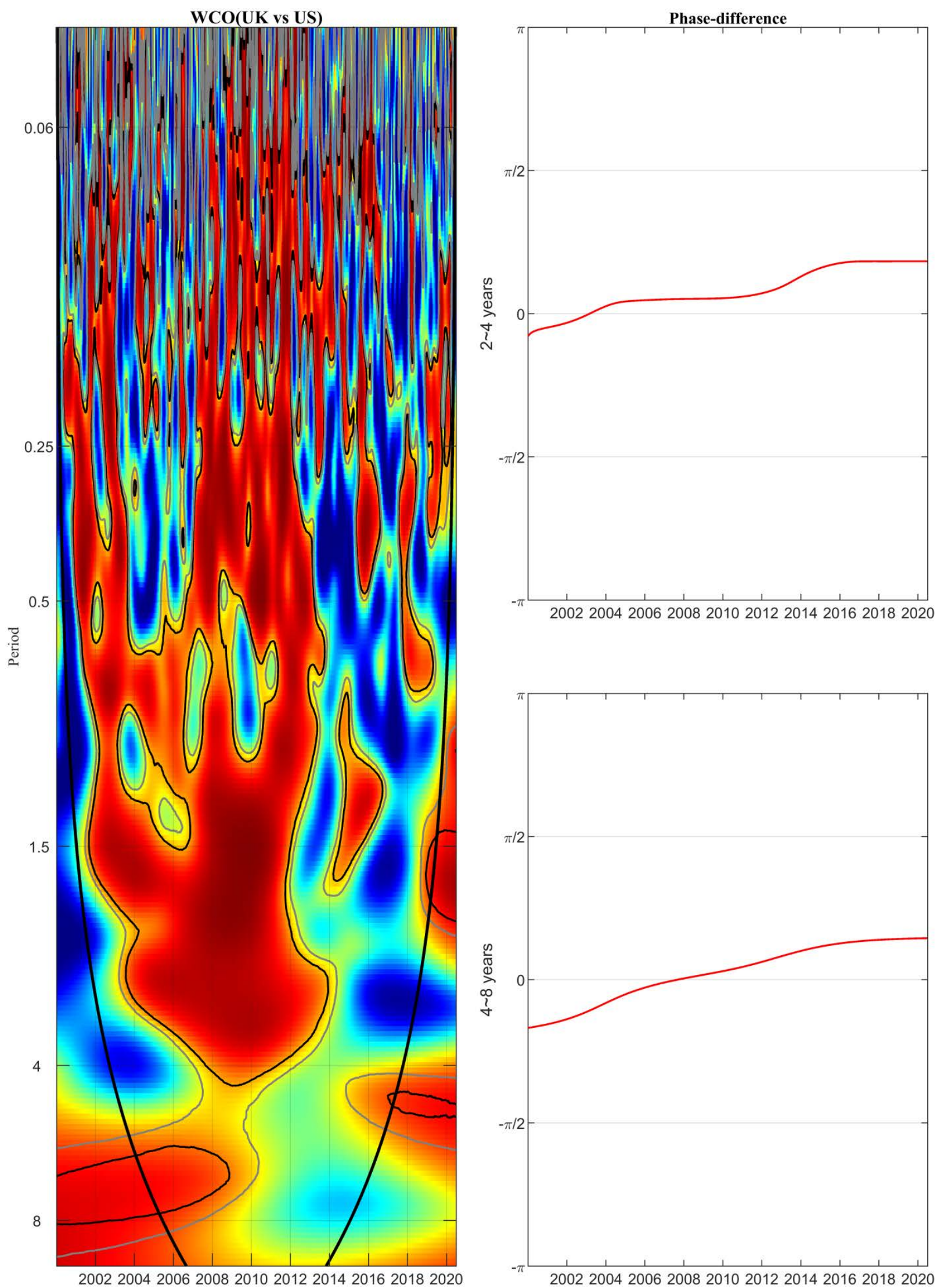

Figure 4. Wavelet coherency between the UK and the USA. 
countries in the coherency between the two countries. Figure 5 shows the partial coherency between France and each country after eliminating the effects of other countries. One noticeable feature of partial coherency is that the regions of higher coherency reduced after eliminating the effects of other countries. This suggests that the wavelet coherency reflects the increasing globalisation of financial markets. There will be reduced coherency between two financial markets, as shown by the partial wavelet coherency, without such a globalised financial market. The partial coherence in the lower periods (2 - 4 years) shows that Germany leads France in a phase relation between 2010 and 2016. However, France and the UK synchronised with the phase difference lying at zero between 2006 and 2012. While there is synchronisation in the lower periods between France and the UK, this occurred in dispersed small islands of regions. However, there was synchronisation between France and Germany and France and the UK in higher periods ( 4 - 8 years) between 2004 and 2016. In contrast, France and the US exhibited an anti-phase relation in higher periods between 2004 and 2016, with France leading.

Figure 6 shows the partial wavelet coherency between Germany and two other countries - the UK and the US. The partial wavelet coherency between Germany and these two countries departs from the previous wavelet coherency between Germany and these countries. After controlling for the effects of other countries, the wavelet partial coherency showed that Germany and the UK are in phase relation between 2002 and 2004 and 2011 and 2016 in the lower periods ( 2 - 4 years). In the same lower periods, Germany and the US synchronised between 2003 and 2007 and between 2014 and 2016. However, most of the time, Germany and the UK exhibited an anti-phase relation in higher periods (4-8 years). They synchronised between 2005 and 2016, with the phase difference lying at zero.

Figure 7 shows the partial wavelet coherency between the UK and the USA. In the lower periods ( 2 - 4 years), UK synchronised with the USA until 2005 before it evolved into a phase relation with the USA leading. However, the two countries were in phase relation in higher periods ( $4-8$ years) with the UK leading in the relation.

The wavelet coherency and the partial wavelet coherency were used to evaluate the link between the equity indexes of the two countries. However, the partial wavelet coherency offers a better perspective on the dynamics of equity markets in two countries as it removes the effect of other countries. Apart from a few exceptional cases, the partial wavelet coherency shows either synchronisation or phase relation between two markets. In the case of synchronisation, the phase difference lies at zero. This implies both equity market increases or decreases at the same time. While the phase relation shows that two markets evolve in the same direction, the equity market in one country triggers this relation. The implication of this result is that there is a huge co-movement in the four markets. However, there is a higher co-movement in the higher periods than in the lower periods. 


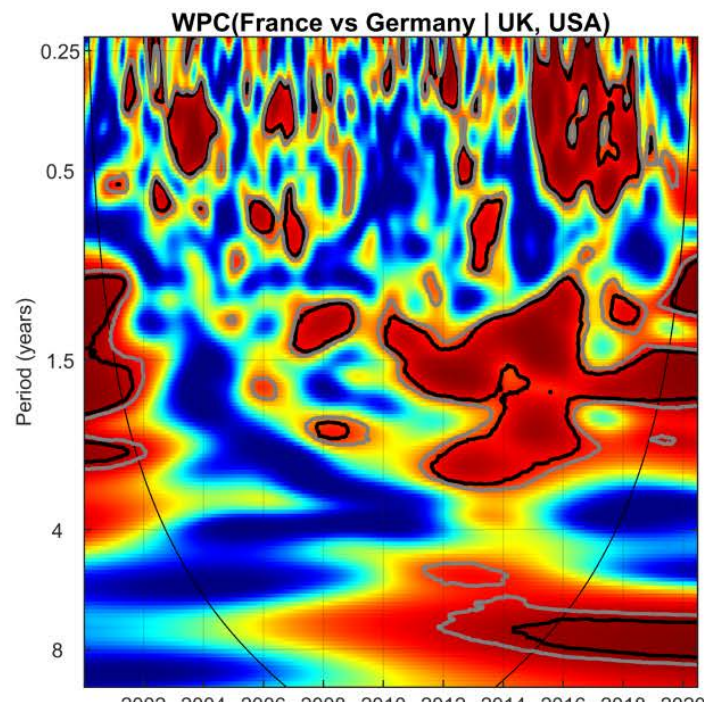

2002200420062008201020122014201620182020

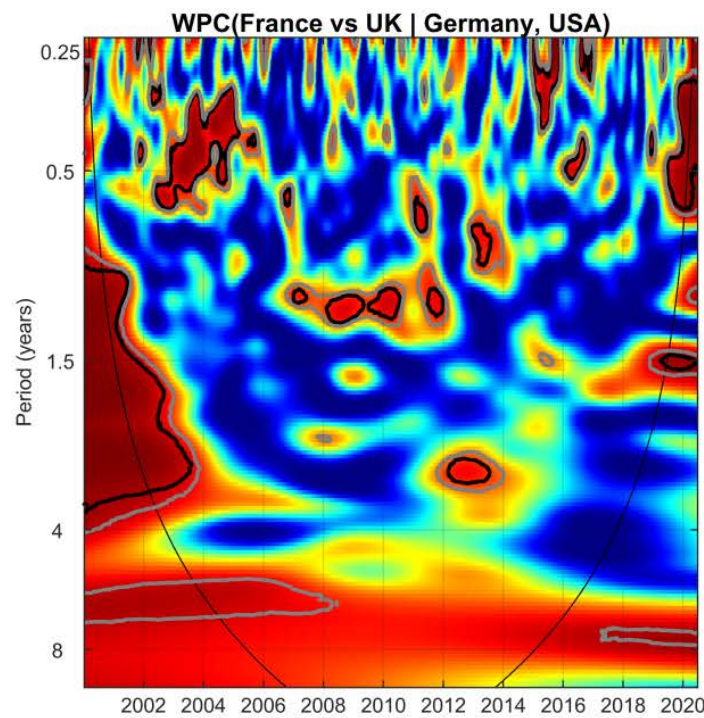

2002200420062008201020122014201620182020

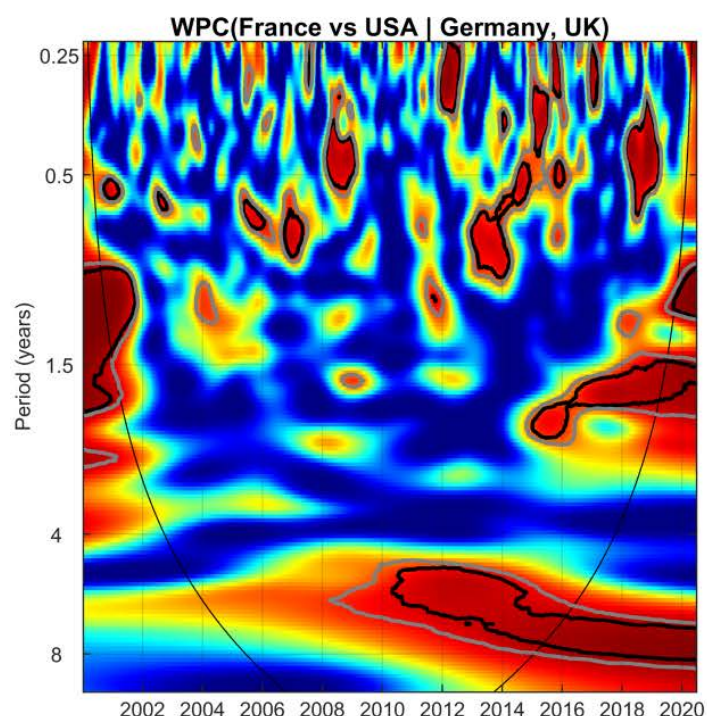

2002200420062008201020122014201620182020
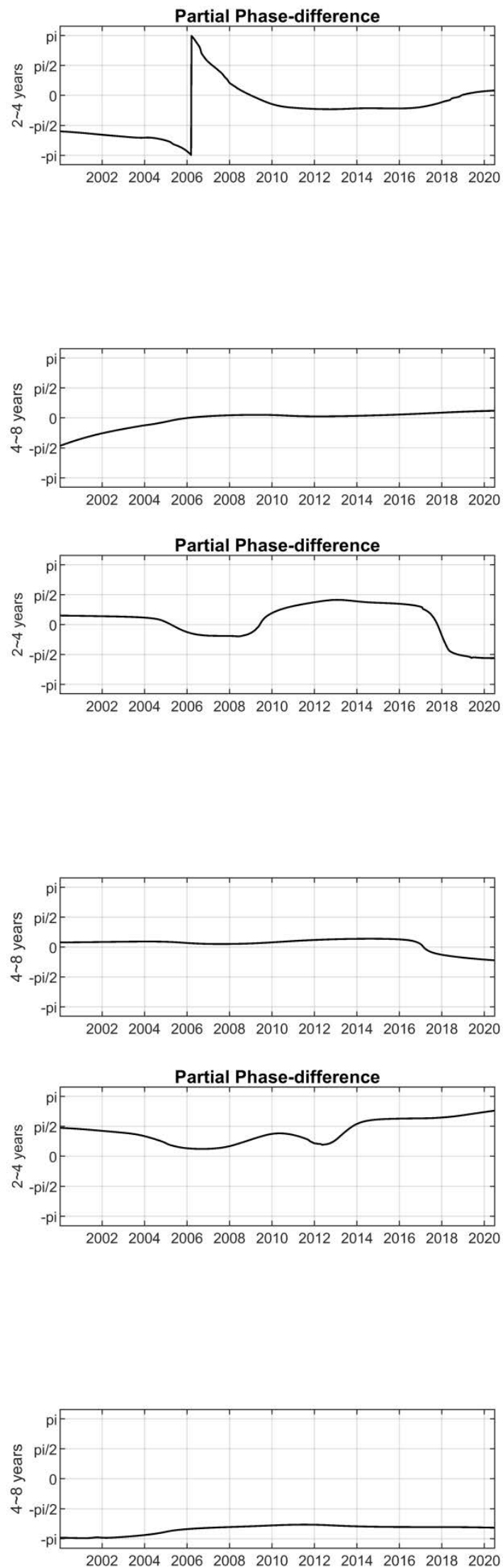

Figure 5. Partial wavelet coherency between France and other countries. 

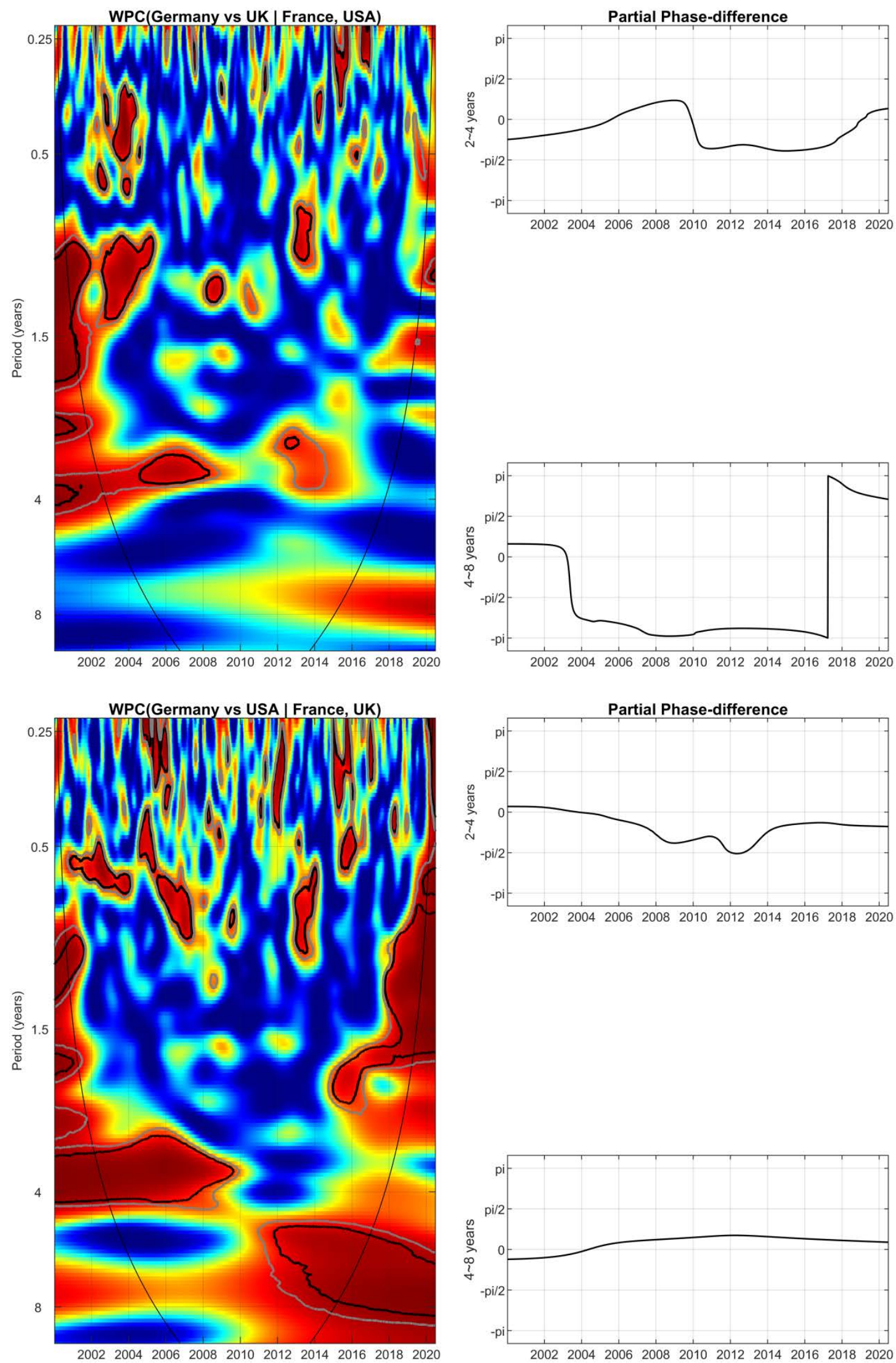

Figure 6. Partial wavelet coherency between Germany and UK and US. 

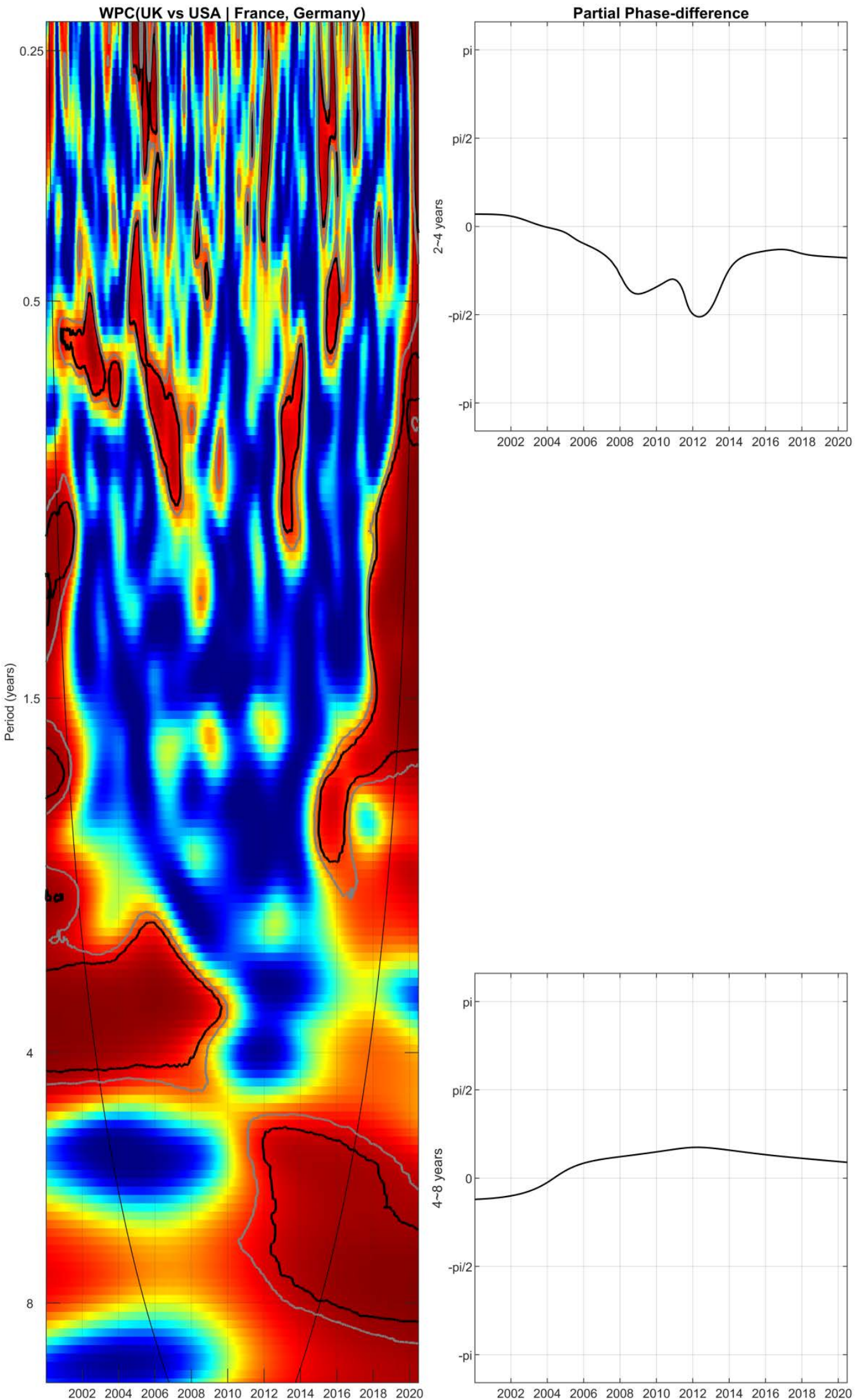

Figure 7. Partial wavelet coherency between UK and USA. 
This suggests that the four markets co-move in the long run. This is expected considering the market size and their influence in the respective geographical locations. The four markets capitalise on the quality of their economies, as they typically enjoy a flight-to-quality from investors from weaker economies. This result corroborates the findings of [26] who established stronger co-movement at lower frequencies (higher periods), and this increases during the turbulent period of the last global financial crisis of 2007/2008. Such co-movement was equally established during the Eurozone crisis. Similarly, the result aligns with [27] who established that co-movement is frequency-dependent and affirmed a stronger co-movement at lower frequencies.

The long-run higher co-movement in the four markets reignites the debate about the effectiveness of portfolio diversification strategy across different markets. Portfolio diversification helps to minimise the overall risk of the portfolio. Diversification strategy across these four markets might not be effective since the four markets have phase relations in the long run. This implies that a decrease in one market will lead to a resultant decline in other markets, maximising the overall risk of the portfolio. Although [28] established the benefits of investing across countries, they found that gains from cross country portfolio diversification are large for high-risk countries. However, the four countries utilised in this study are relatively low-risk countries.

\section{Conclusion}

The study used continuous wavelet tools to evaluate the co-movement of market returns in four countries. The paper utilised the market indexes in these four countries and used four wavelet tools-wavelet spectrum, wavelet coherency, partial wavelet-coherency and phase difference-to evaluate the co-movement. While the wavelet coherency explored the link between equity markets in two countries, the link did not disentangle the effect of other countries. The partial wavelet coherency was used to remove the effects of other countries in the link and the study found co-movement among equity indexes in the four countries. However, market co-movement is dependent on the investment horizon. The paper particularly established higher co-movement in the long run, suggesting that the four markets either synchronise or move in the same direction with one market championing the movement in the long run.

\section{Conflicts of Interest}

The author declares no conflicts of interest regarding the publication of this paper.

\section{References}

[1] Lettau, M. and Ludvigson, S.C. (2010) Measuring and Modelling Variation in the Risk-Return Trade-Off. In: Aït-Sahalia, Y. and Hansen, L.P., Eds., Handbook of Financial Econometrics. Tools and Techniques, North-Holland Publishing, Amsterdam, 617-690. https://doi.org/10.1016/B978-0-444-50897-3.50014-6 
[2] Ghysels, E., Santa-Clara, P. and Valkanov, R. (2005) There Is a Risk-Return TradeOff after All. Journal of Financial Economics, 76, 509-548. https://doi.org/10.1016/j.jfineco.2004.03.008

[3] Merton, R.C. (1973) An Intertemporal Capital Asset Pricing Model. Econometrica: Journal of the Econometric Society, 41, 867-887. https://doi.org/10.2307/1913811

[4] Bali, T.G. and Engle, R.F. (2010) The Intertemporal Capital Asset Pricing Model with Dynamic Conditional Correlations. Journal of Monetary Economics, 57, 377390. https://doi.org/10.1016/j.jmoneco.2010.03.002

[5] Bollerslev, T., Osterrieder, D., Sizova, N. and Tauchen, G. (2013) Risk and Return: Long-Run Relations, Fractional Cointegration, and Return Predictability. Journal of Financial Economics, 108, 409-424. https://doi.org/10.1016/j.jfineco.2013.01.002

[6] Kinnunen, J. (2014) Risk-Return Trade-Off and Serial Correlation: Do Volume and Volatility Matter? Journal of Financial Markets, 20, 1-19. https://doi.org/10.1016/j.finmar.2014.04.003

[7] Lynch, P.E. and Zumbach, G.O. (2003) Market Heterogeneities and the Causal Structure of Volatility. Quantitative Finance, 3, 320-331. https://doi.org/10.1088/1469-7688/3/4/308

[8] Masset, P. (2008) Analysis of Financial Time-Series Using Fourier and Wavelet Methods. SSRN, Article ID: 1289420. https://doi.org/10.2139/ssrn.1289420

[9] El Alaoui, A.O., Dewandaru, G., Rosly, S.A. and Masih, M. (2015) Linkages and Comovement between International Stock Market Returns: Case of Dow Jones Islamic Dubai Financial Market Index. Journal of International Financial Markets, Institutions and Money, 36, 53-70. https://doi.org/10.1016/j.intfin.2014.12.004

[10] Gencay, R., Selcuk, F. and Whitcher, B.J. (2001) An Introduction to Wavelets and Other Filtering Methods in Finance and Economics. Academic Press, Cambridge. https://doi.org/10.1016/B978-012279670-8.50004-5

[11] Graps, A. (1995) An Introduction to Wavelets. IEEE Computational Science and Engineering, 2, 50-61. https://doi.org/10.1109/99.388960

[12] Ogden, T. (1997) Essential Wavelets for Statistical Applications and Data Analysis. Birkhäuser, Boston.

[13] Candelon, B., Piplack, J. and Straetmans, S. (2008) On Measuring Synchronization of Bulls and Bears: The Case of East Asia. Journal of Banking \& Finance, 32, 1022 1035. https://doi.org/10.1016/j.jbankfin.2007.08.003

[14] Arouri, M.E. H., Jouini, J. and Nguyen, D.K. (2013) On the Relationship between World Oil Prices and GCC Stock Markets.

[15] Cheng, A.R. and Jahan-Parvar, M.R. (2014) Risk-Return Trade-off in the Pacific Basin Equity Markets. Emerging Markets Review, 18, 123-140. https://doi.org/10.1016/j.ememar.2014.01.004

[16] Salvador, E., Floros, C. and Arago, V. (2014) Re-Examining the Risk-Return Relationship in Europe: Linear or Non-Linear Trade-Off? Journal of Empirical Finance, 28, 60-77. https://doi.org/10.1016/j.jempfin.2014.05.004

[17] Christensen, B.J., Nielsen, M.O. and Zhu, J. (2015) The Impact of Financial Crises on the Risk-Return Trade-Off and the Leverage Effect. Economic Modelling, 49, 407-418. https://doi.org/10.1016/j.econmod.2015.03.006

[18] Wu, S.J. and Lee, W.-M. (2015) Intertemporal Risk-Return Relationships in Bull and Bear Markets. International Review of Economics \& Finance, 38, 308-325. https://doi.org/10.1016/j.iref.2015.03.008

[19] Chang, K.L. (2016) Does the Return-State-Varying Relationship between Risk and 
Return Matter in Modelling the Time Series Process of Stock Return? International Review of Economics \& Finance, 42, 72-87. https://doi.org/10.1016/j.iref.2015.10.018

[20] Wang, Z. and Khan, M.M. (2017) Market States and the Risk-Return Trade-Off. The Quarterly Review of Economics and Finance, 65, 314-327.

https://doi.org/10.1016/j.qref.2016.10.001

[21] Debnath, L. and Shah, F.A. (2002) Transforms and Their Applications. Springer, Boston. https://doi.org/10.1007/978-1-4612-0097-0

[22] Addison, P.S. (2017) The Illustrated Wavelet Transform Handbook: Introductory Theory and Applications in Science, Engineering, Medicine and Finance. CRC Press, Boca Raton.

[23] Gallegati, M., Gallegati, M., Ramsey, J.B. and Semmler, W. (2014) Does Productivity Affect Unemployment? A Time-Frequency Analysis for the US. In: Gallegati, M. and Semmler, W., Eds., Wavelet Applications in Economics and Finance, Springer, Cham, 23-46. https://doi.org/10.1007/978-3-319-07061-2 2

[24] Aguiar-Conraria, L. and Soares, M.J. (2014) The Continuous Wavelet Transforms: Moving Beyond Uni- and Bivariate Analysis. Journal of Economic Surveys, 28, 344375. https://doi.org/10.1111/joes.12012

[25] Thao, T.P. and Daly, K. (2012) The Impacts of the Global Financial Crisis on Southeast-Asian Equity Markets Integration. International Journal of Trade, Economics and Finance, 3, 299-304. https://doi.org/10.7763/IJTEF.2012.V3.216

[26] Kiviaho, J., Nikkinen, J., Piljak, V. and Rothovius, T. (2014) The Co-Movement Dynamics of European Frontier Stock Markets. European Financial Management, 20, 574-595. https://doi.org/10.1111/j.1468-036X.2012.00646.x

[27] Rua, A. and Nunes, L.C. (2009) International Co-Movement of Stock Market Returns: A Wavelet analysis. Journal of Empirical Finance, 16, 632-639. https://doi.org/10.1016/j.jempfin.2009.02.002

[28] Driessen, J. and Laeven, L. (2007) International Portfolio Diversification Benefits: Cross-Country Evidence from a Local Perspective. Journal of Banking \& Finance, 31, 1693-1712. https://doi.org/10.1016/j.jbankfin.2006.11.006 